\section{The Bioethics Network of Ohio (BENO)}

\section{BRENDEN MINOGUE}

The Bioethics Network of Ohio (BENO) has existed for about 2 years. Our first steering committee meeting took place at Case Western Reserve University in June 1990. About 15 people came to this first meeting, and since then BENO has grown to over 300 members. We have two kinds of members. Individuals, such as doctors, nurses, healthcare administrators, educators, and members of ethics committees, compose the bulk of our members. However, hospitals, nursing homes, and other healthcare institutions have joined as institutional members.

One of our main goals is to increase communication among those professionals in the state who have a genuine interest in the problems of bioethics. Most of our members have had valuable practical experience in the area of bioethics. They serve on ethics committees, or teach bioethics in universities or hospitals, or have administrative responsibility in the management of bioethical dilemmas that emerge within a given healthcare setting.

To achieve our goal of enhancing communication, the network has taken on four responsibilities. First, we have set up an electronics network that allows the membership to communicate with one another instantaneously. We are "on line" through the Cleveland
Freenet and Case Western Reserve University's Telecomputing Laboratory. Cleveland State University's Bioethics Certificate Program not only has given us a vast amount of assistance in providing and maintaining our network hardware but also has given us a solid system operator, Jenny Gabriel, who manages the flow of information into the network. We have introduced a lot of people to the joys of electronic communication, but we have much more work to do before we can realize the unbelievable potential of electronic networking.

Second, we have started a hard copy newsletter appropriately entitled The BENO Newsletter. The Newsletter keeps our membership up to date on topics such as the Patient Self-Determination Act and the state's new advance directive law. The Newsletter also assists our membership to adapt to our "on line" facilities. Finally, every issue ends with a bioethics case study, along with commentary from two opposing perspectives. The Newsletter is a genuine asset to the Network.

Third, we have organized two statewide conferences at which the membership convenes. Our first conference was held in the northeast part of the state at Case Western Reserve University's School of Law in June 1991. We held our second meeting (June 1992) at Ohio Dominican College in the central part of the state in Columbus. We were more than pleased with our enrollments at both conferences; over 125 people at- 
tended each of these meetings. One of the highlights of our last meeting was a Policy Table to which our members brought their institutional ethics policies and discussed some of the virtues and vices of these policies.

Fourth, we have divided the state into four regions, which we have called regional forums, to facilitate the development of more frequent, smaller meetings. These forums provide members with the opportunity to participate in and respond to current bioethics problems within the state and the nation. Our Newsletter and our electronic bulletin board print summaries of the forums' discussions. These forums are not miniconferences. Rather, they are participant driven in that they strive to stimulate discussion among our members.

Our network leadership has many future goals. First, we would like to become effective instruments for educating hospitals, nursing homes, and other healthcare institutions about ethics committees. Second, at the conclusion of our last statewide meeting, we reached a consensus regarding the need for BENO to make recommendations to the state legislature regarding changes in the advance directive law. This law went into effect in October 1991, and complaints throughout the state have been flowing into BENO since its inception. We are still at the discussion stage of this project, but given the energy that already is present in the network, I think that we will soon reach agreement on how to proceed with this task.

\section{West Virginia Network of Ethics Committees}

\section{ALVIN H. MOSS}

After 4 years of being a consortium of interested healthcare professionals and administrators, the West Virginia Network of Ethics Committees formalized its status as a dues-paying organization with membership in 1991. The purpose of the West Virginia Network of Ethics Committees is to educate healthcare professionals and the public in West Virginia about ethical issues in healthcare, to serve as a resource for them in analyzing ethical dilemmas in patient care, to assist hospitals, nursing homes, hospices, and home healthcare agencies to start or strengthen ethics committees, and, as a result of all these functions, to improve patient care in West Virginia.

Members of the Network, designated Friends, pay annual membership dues of $\$ 500$ and receive the following services:

1) two conferences each year on current, relevant topics in health ethics with nationally prominent speakers;

2) a 500-page annotated bibliography of up-to-date articles on health ethics that covers 17 topic areas;

3) a newsletter published three times each year, which includes articles on health ethics and recent healthcare legislation;

4) assistance in starting and/or strengthening their institutional ethics committees;

5) a "hotline" accessible for information and advice about health ethics problems;

6) a speaker's bureau to assist members in educating their health professionals and community;

7) the latest information on the use of advance directives; and

8) a Network forum that meets twice each year to discuss difficult cases, analyze recently developed institutional policies on ethically sensitive issues, and present an overview of timely topics in health ethics. 